\title{
Oxidation Mechanism of Nickel Oxide/Carbon Nanotube Composite
}

\author{
Tae-Hoon Kim, ${ }^{1}$ Min-Ho Park, ${ }^{1}$ Jiho Ryu, ${ }^{2}$ and Cheol-Woong Yang ${ }^{1, *}$ \\ ${ }^{1}$ School of Advanced Materials Science and Engineering, Sungkyunkwan University, Suwon, Gyeonggi-do 440-746, \\ South Korea \\ ${ }^{2}$ Department of Automobile Development, Ajou Motor College, Boryeong 355-769, Korea
}

\begin{abstract}
The oxidation mechanism and thermal stability of nickel oxide (NiO)/carbon nanotube (CNT) composites were investigated by examining composites with different $\mathrm{NiO}$ contents by thermogravimetric analysis and transmission electron microscopy (TEM). NiO acts as a catalyst in the oxidation of CNT in the composite. CNTs can be oxidized, even in a vacuum, by reducing $\mathrm{NiO}$ to nickel at temperatures lower than the normal oxidation temperature of CNTs. This phase transition was confirmed directly by in situ heating TEM observations. In air, reduction by CNT occurs simultaneously with reoxidation by gaseous $\mathrm{O}_{2}$ molecules, and $\mathrm{NiO}$ maintains its phase. The thermal stability decreased with increasing $\mathrm{NiO}$ content because of defects in the $\mathrm{CNT}$ generated by the $\mathrm{NiO}$ loading.
\end{abstract}

Key words: oxidation mechanism, NiO, CNT, composite, in situ heating, TEM, TGA, Raman spectroscopy

\section{INTRODUCTION}

Carbon nanotubes (CNTs), which were first discovered in 1991 by Iijima (1991), have been examined for many applications owing to their excellent properties. CNTs have great potential for a wide range of applications owing to their electrical, thermal, and mechanical properties (Avouris et al., 2007). In addition, the large specific area and small size of the CNTs make them suitable catalyst supports for catalytically active metal and/or metal oxide particles. Therefore, various metal/CNT and metal oxide/CNT composites have been investigated to take full advantage of the multifunctionality of the metal, metal oxide, and CNTs. In the case of metal oxide/CNT composites, CNT can provide a great reaction site because of the large specific area and high electronic conduction path to the metal oxide, which itself has relatively low conductivity (Avouris et al., 2007). Therefore, CNTs are expected to increase the electrochemical utilization of metal oxide. Among the various metal oxides, nickel oxide $(\mathrm{NiO})$ is attractive in view of its low cost, low toxicity, well-defined electrochemical redox activity, and the possibility of enhanced performance through different preparative methods (He et al., 2006). For these reasons, NiO/ CNT composites have been studied widely for many possible applications, such as catalysts, electrochromic films, gas sensors, and electrode materials (Xia et al., 2008; Wang et al., 2008; Lota et al., 2011).

For many applications, it is important to understand the oxidation resistance and thermal stability of CNTs in a $\mathrm{NiO} / \mathrm{CNT}$ composite because they can limit the operation temperature and applicability of the composites. In general, CNTs are oxidized at $600-700^{\circ} \mathrm{C}$ (Ajayan et al., 1995). On the other hand, catalyst residues, amorphous carbon, and

(๑) MICROSCOPY SOCIETY OF AMERICA 2013

${ }^{\star}$ Corresponding author. E-mail: cwyang@skku.edu defects can reduce considerably their oxidative stability toward air. In contrast, the oxidative stability can be enhanced by high-temperature vacuum annealing, which produces more graphitic CNTs with a low defect concentration (Osswald et al., 2005; Behler et al., 2006). In addition, in NiO/ CNT composites, the oxidation resistance and temperature of CNT can be affected by $\mathrm{NiO}$ around the CNT, and the oxidation state of the $\mathrm{NiO} / \mathrm{CNT}$ composite can affect its characteristics and performance (Li et al., 2004; Aksel \& Eder, 2010). Therefore, the oxidation mechanism and thermal stability of $\mathrm{NiO} / \mathrm{CNT}$ composite should be examined in detail.

In this study, $\mathrm{NiO} / \mathrm{CNT}$ composites with different $\mathrm{NiO}$ contents were prepared using a solution-based method. Thermogravimetric analysis (TGA) in air and $\mathrm{N}_{2}$ confirmed the $\mathrm{NiO}$ loading on CNT and the decrease in oxidation temperature with increasing $\mathrm{NiO}$ content. The oxidation mechanism was predicted from these data. Transmission electron microscopy (TEM), with ex situ and in situ heat treatment, was used to observe the microstructure.

\section{Materials and Methods}

$\mathrm{NiO} / \mathrm{CNT}$ composites were prepared by the thermal decomposition of nickel nitrate on CNTs. Multi-walled carbon nanotubes (MWCNT, M95, Carbon Nano-Material Technology Co. Ltd.) and $\mathrm{N}_{2} \mathrm{NiO}_{6} \cdot 6 \mathrm{H}_{2} \mathrm{O}$ with various contents (10, 30,50 and $80 \mathrm{wt} \% \mathrm{NiO}$ ) were dissolved in ethanol. The samples were heat-treated in vacuum for $1 \mathrm{~h}$ at $300^{\circ} \mathrm{C}$ for the thermal decomposition of $\mathrm{N}_{2} \mathrm{NiO}_{6} \cdot 6 \mathrm{H}_{2} \mathrm{O}$ to $\mathrm{NiO}$ (Brockner et al., 2007). Subsequently, TGA (TA Instruments Q500) was conducted to determine the $\mathrm{NiO}$ loading on the CNT and examine the variations of the oxidation temperature as a function of the $\mathrm{NiO}$ content and atmosphere (air and $\mathrm{N}_{2}$ ). The samples were analyzed in a platinum pan from room 
temperature to $900^{\circ} \mathrm{C}$ at a heating rate of $5^{\circ} \mathrm{C} / \mathrm{min}$. Raman spectroscopy (Renishaw RM 1000-In Via) was used to examine the quantity of defects in the CNTs. The ex situ heat treatment was conducted at $600^{\circ} \mathrm{C}$ for $30 \mathrm{~min}$ in vacuum or in air. TEM (JEM-2100F, JEOL Co. Ltd.) was employed to observe microstructure of the $\mathrm{NiO}(50 \mathrm{wt} \%) / \mathrm{CNT}$ composite. In addition, selected area diffraction (SAD) was used to confirm the phase transition. The in situ heating experiments were performed in the TEM (JEM-3011 with a $\mathrm{LaB}_{6}$ filament operating at $300 \mathrm{keV}$, JEOL Co. Ltd.). A model EM-21130 JEOL heating holder was used to resistively heat the samples.

\section{Results AND Discussion}

Figure 1 shows TGA results of the $\mathrm{NiO} / \mathrm{CNT}$ composite with various $\mathrm{NiO}$ contents in air and $\mathrm{N}_{2}$. Weight losses were observed in each sample and derivative plots were obtained in both atmospheres. The NiO loading after CNT oxidation was confirmed by the weight loss curves in air. The amount of residue remaining increased with increasing $\mathrm{NiO}$ loading (see Fig. 1a). On the other hand, in $\mathrm{N}_{2}$ atmosphere, there was less residue remaining (see Fig. 1b). Derivative plots (DTG) in $\mathrm{N}_{2}$ revealed peaks at $\sim 540^{\circ} \mathrm{C}$ (Fig. 1b). In contrast, in air, the peaks were observed at $\sim 400^{\circ} \mathrm{C}$ with increasing $\mathrm{NiO}$ content from 10 to $80 \mathrm{wt} \%$ (Fig. 1a). As a reference, the MWCNTs, which were used for this study, were oxidized at $\sim 600^{\circ} \mathrm{C}$ (data not shown). In other words, $\mathrm{NiO}$ affects the oxidation stability and decreases the oxidation temperature of CNT. The main peaks at $\sim 540^{\circ} \mathrm{C}$ in both atmospheres are believed to have occurred via the same mechanism. Unlike an air atmosphere, which supplies oxygen continuously, in a $\mathrm{N}_{2}$ atmosphere, there is no oxygen source to oxidize the CNTs except for the oxygen in NiO itself. Therefore, the CNTs were oxidized at the interface between $\mathrm{NiO}$ and CNT by consuming oxygen from the $\mathrm{NiO}$ and reducing $\mathrm{NiO}$ to nickel. This was confirmed by TGA in $\mathrm{N}_{2}$ atmosphere, which showed less residue with increasing $\mathrm{NiO}$ loading (see Fig. 1b). The number of reaction sites that cause CNT oxidation increased with increasing $\mathrm{NiO}$ content, and more oxygen could be consumed through CNT oxidation. Consequently, less residue remained in the $\mathrm{N}_{2}$ atmosphere. In the air atmosphere, however, oxygen vacancies generated by the oxidation of CNT diffuse from the interface between $\mathrm{NiO}$ and $\mathrm{CNT}$ to the surface of $\mathrm{NiO}$ and are regenerated by gas-phase oxygen (Mars \& Krevelen, 1954; Aksel \& Eder, 2010). Therefore, in air atmosphere, $\mathrm{NiO}$ can keep its phase without a transition to nickel, and the amount of residue shown in the TGA results (Fig. 1a) can be understood in the same context.

To confirm and observe the microstructure and phase transition directly through the oxidation of CNT by reducing $\mathrm{NiO}$ to nickel, comparative TEM analysis was conducted selectively for the $\mathrm{NiO}(50 \mathrm{wt} \%) / \mathrm{CNT}$ composite samples before and after the ex situ heat treatment at $600^{\circ} \mathrm{C}$ for $30 \mathrm{~min}$ in vacuum and air atmosphere. Figure 2 shows the TEM results before and after heat treatment. After heating in a vacuum, the phase transition of $\mathrm{NiO}$ to nickel was
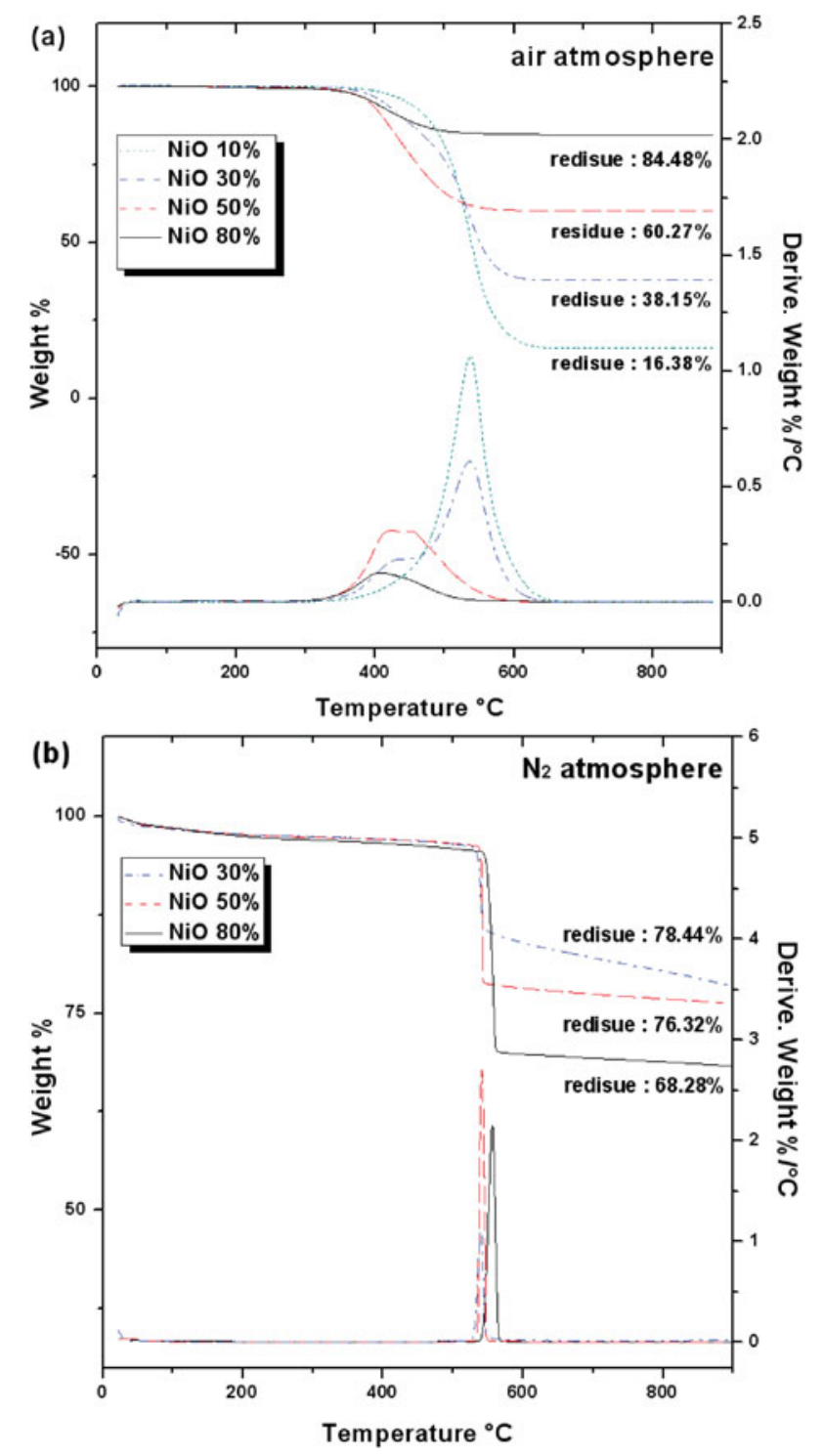

Figure 1. TGA results of $\mathrm{NiO} / \mathrm{CNT}$ composite with various $\mathrm{NiO}$ contents $(10,30,50$, and $80 \mathrm{wt} \%)$ in (a) air and (b) $\mathrm{N}_{2}$ atmosphere. TGA, thermogravimetric analysis; NiO, nickel oxide; CNT, carbon nanotube.

confirmed by the SAD pattern and fast Fourier transform (FFT) image (Figs. 2b, 2d). During the oxidation of CNT by reducing $\mathrm{NiO}$ to nickel in a vacuum, the oxygen in $\mathrm{NiO}$ diffuses to the CNT surface and carbon diffuses into nickel because carbon has some solid solubility in nickel (Singleton \& Nash, 1989). This was confirmed by the formation of graphitic shell covering the nickel particles, which was formed by the precipitation of supersaturated carbon from nickel with cooling down (Fig. 2b). In contrast, $\mathrm{NiO}$ in the sample after heating in air maintains its phase without a transition because reduction by CNT and reoxidation by gaseous $\mathrm{O}_{2}$ molecules in $\mathrm{NiO}$ occur simultaneously (Fig. 2c).

The oxidation mechanism of CNT with reducing $\mathrm{NiO}$ can be explained using the Ellingham Diagram. To oxidize CNT, $\mathrm{O}_{2}$ molecules were adsorbed on the CNT surface first, a $\mathrm{C}-\mathrm{O}$ bond was formed, and the $\mathrm{C}-\mathrm{O}$ pair was desorbed 

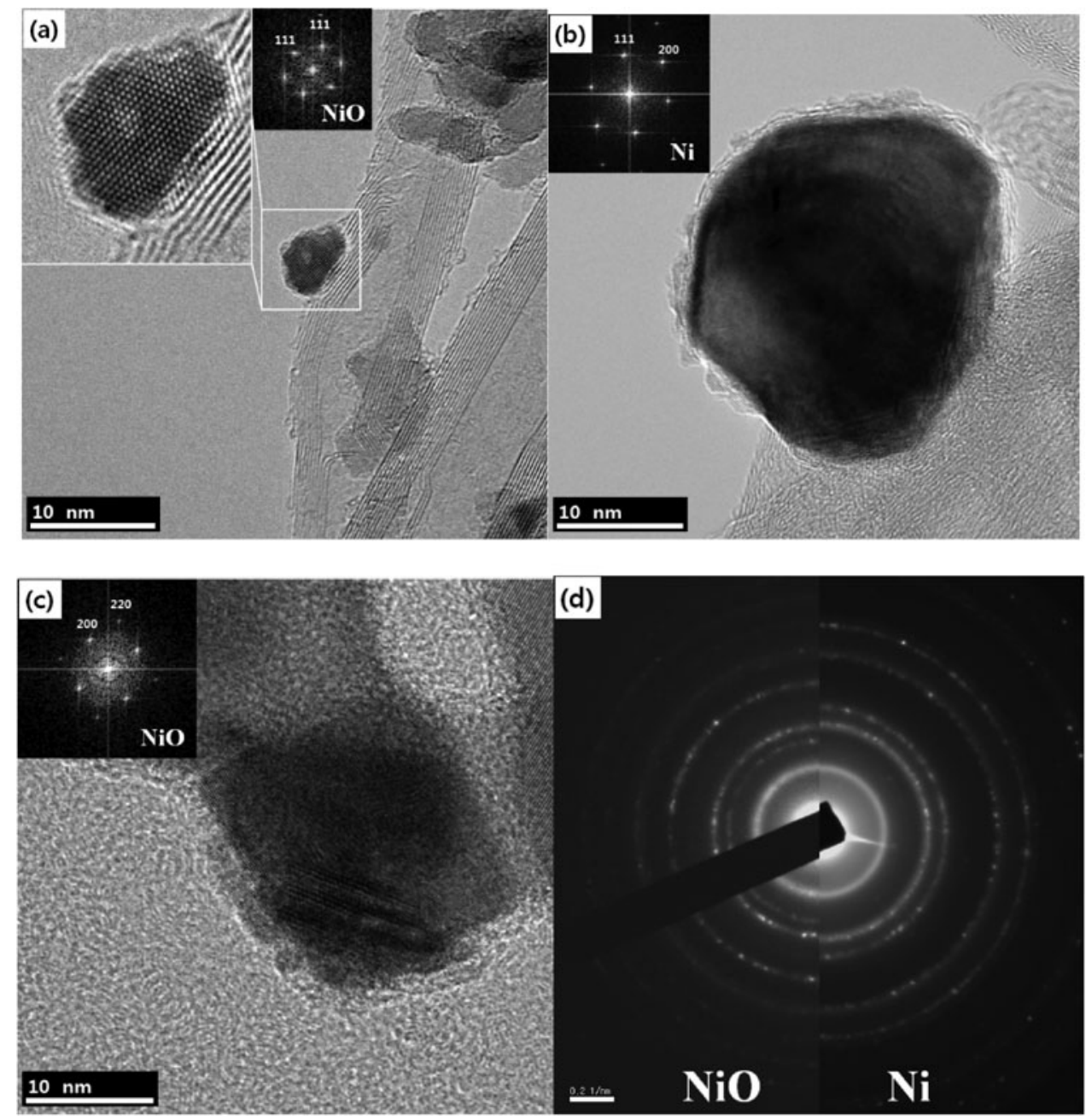

Figure 2. TEM results before and after ex situ heat treatment. a: NiO particle on CNT before heat treatment. b: Nickel particle on CNT after heat treatment in a vacuum. c: NiO particle after heat treatment in air. d: SAD pattern before and after heat treatment in a vacuum, which shows a phase transition from $\mathrm{NiO}$ to nickel. TEM, transmission electron microscopy; $\mathrm{NiO}$, nickel oxide; $\mathrm{CNT}$, carbon nanotube; SAD, selected area diffraction.

with breaking C-C bonds (Zhu et al., 2000; Park et al., 2001). In the Ellingham Diagram, the position of the line for a given reaction shows the stability of the oxide as a function of temperature and can determine the relative ease of reducing a given metallic oxide to metal. Reactions closer to the top of the diagram are the most noble metals, and their oxides are unstable and reduced easily. Toward the bottom of the diagram, the metals become progressively more reactive and their oxides become more difficult to reduce (Ellingham, 1944). To examine the reduction of $\mathrm{NiO}$ by $\mathrm{CNT}$, the $2 \mathrm{Ni}+\mathrm{O}_{2} \Rightarrow 2 \mathrm{NiO}$ line and $2 \mathrm{C}+\mathrm{O}_{2} \Rightarrow 2 \mathrm{CO}$ line can be used because a $\mathrm{CO}$ molecule was desorbed from the adsorbed phases by breaking the $\mathrm{C}-\mathrm{C}$ bonds after $\mathrm{O}_{2}$ adsorption. Both lines are crossed at $\sim 500^{\circ} \mathrm{C}$. At temperatures $<500^{\circ} \mathrm{C}$, the $2 \mathrm{C}+\mathrm{O}_{2} \Rightarrow 2 \mathrm{CO}$ line takes place at the bottom of the $2 \mathrm{Ni}+\mathrm{O}_{2} \Rightarrow 2 \mathrm{NiO}$ line and CNT cannot be oxidized by reducing $\mathrm{NiO}$. On the other hand, at temperatures $>500^{\circ} \mathrm{C}$, the positions of both lines are reversed and the heat of formation of carbon monoxide is smaller than $\mathrm{NiO}$ at $\sim 500^{\circ} \mathrm{C}$. Therefore, the main DTG peak at $\sim 540^{\circ} \mathrm{C}$ in the
TGA results in air and $\mathrm{N}_{2}$ atmospheres with the same mechanism, i.e., because of the oxidation of CNT by consuming oxygen from $\mathrm{NiO}$ and generating oxygen vacancies.

On the other hand, with increasing $\mathrm{NiO}$ loading (50 and $80 \mathrm{wt} \%$ ) in air, the peak moved from $\sim 540$ to $400^{\circ} \mathrm{C}$. This is caused by another mechanism, and is due to defects of CNT, which occur with increasing $\mathrm{NiO}$ content. To quantify the increase in defects due to the $\mathrm{NiO}$ loading, Raman spectroscopy was carried out with excitation at $633 \mathrm{~nm}$. Figure 3 shows the Raman spectra of the CNTs with various $\mathrm{NiO}$ contents. The number of defects can be estimated from the D band in the Raman spectrum. Two characteristic peaks near 1,320 and $1,600 \mathrm{~cm}^{-1}$ were observed in the $\mathrm{NiO} / \mathrm{CNT}$ composites. The former, which is known as the $\mathrm{D}$ band, originates from the first-order scattering process of $\mathrm{sp}^{3}$ carbon by the presence of in-plane substitutional hetero-atoms, vacancies, grain boundaries, or other defects, and by finite size effects; all of these reduce the crystalline symmetry of the quasi-infinite lattice (Brown et al., 2001). The latter, which is known as the G band, 


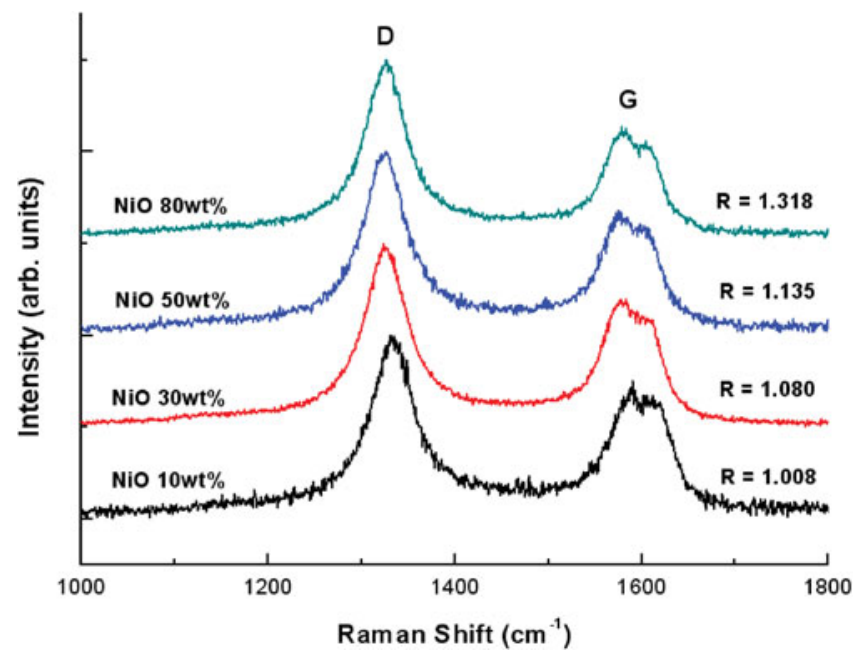

Figure 3. Raman spectra as a function of the NiO loading on CNT. $R$ value (the D band/G band ratio) increases with increasing the amount of loading. $\mathrm{NiO}$, nickel oxide; $\mathrm{CNT}$, carbon nanotube.

represents the $\mathrm{sp}^{2}$ carbon states related to the graphitic hexagon-pinch mode (Osswald et al., 2007). Owing to the origin of the respective bands, the $R$ value (i.e., the $\mathrm{D}$ band/G band ratio) indicates the quantity of defects (disordered carbon) in the tube walls (Lee et al., 2011). More defects are generated on CNTs with increasing $\mathrm{NiO}$ content, which was demonstrated by an increase in $R$ value from 1.008 for $10 \mathrm{wt} \%$ to 1.318 for $80 \mathrm{wt} \%$. The adsorption energy of an $\mathrm{O}_{2}$ molecule on defects is much larger than that on a nondefective tube wall. Furthermore, the desorption barriers of the $\mathrm{C}-\mathrm{O}$ pair from the defects are much lower than those at nondefective wall (Zhu et al., 2000; Park et al., 2001). Therefore, the oxidation rate of disordered carbon and defective tubes by $\mathrm{O}_{2}$ molecules is much faster than that of the nondefective wall and oxidation occurs at $\sim 400^{\circ} \mathrm{C}$ (Osswald et al., 2005; Behler et al., 2006).

The temperature when a phase transition occurs was examined directly by observing the dynamic changes in the diffraction patterns of $\mathrm{NiO}$ as a function of temperature through an in situ heating experiment. Figure 4 shows the in situ results. In the SAD patterns, the (200) plane of nickel began to appear at $\sim 500^{\circ} \mathrm{C}$, and the (111) and (220) plane of $\mathrm{NiO}$ decreased with continued heating. These $e x$ situ and in situ TEM results are consistent with the TGA results.

\section{CONCLUSION}

This study examined the thermal stability and oxidation mechanism of the NiO/CNT composite. The NiO/CNT composites were prepared by a solution-based method with various $\mathrm{NiO}$ contents. The oxidation mechanism was suggested based on the comparative TGA and TEM results in air and $\mathrm{N}_{2}$ atmosphere and Ellingham Diagram. In addition, phase transitions were observed directly by in situ heating TEM. NiO decreases the oxidation temperature of CNTs and acts as a catalyst. CNTs can be oxidized by

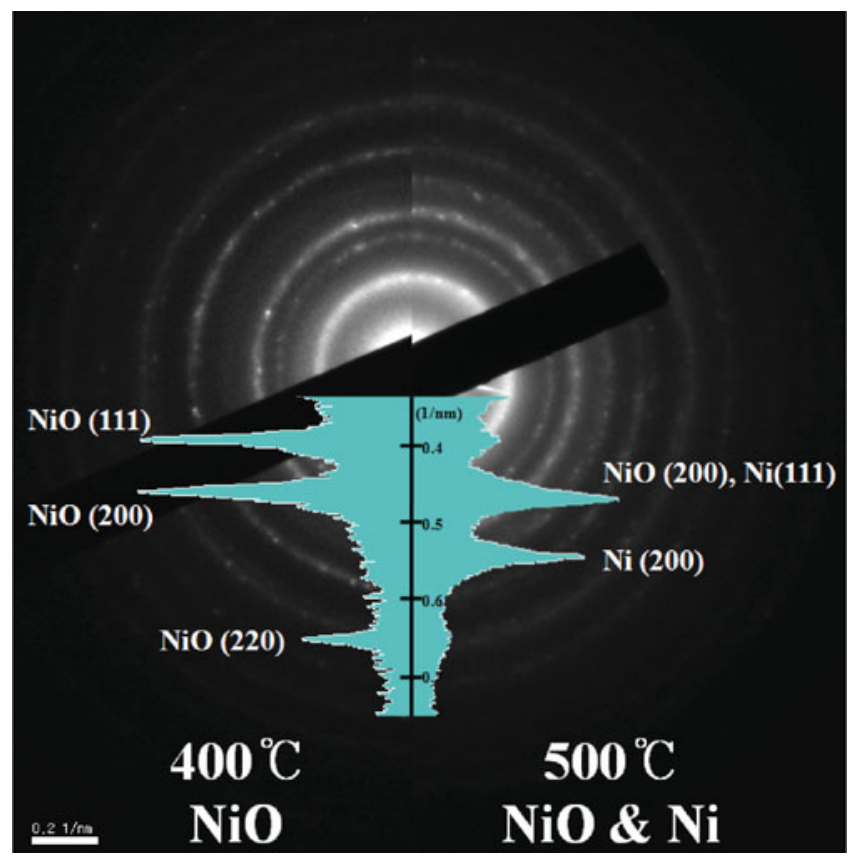

Figure 4. Dynamic change in the SAD patterns during in situ heat treatment performed inside TEM. Nickel (200) plane started to appear at $\sim 500^{\circ} \mathrm{C}$ and $\mathrm{NiO}(111)$ and (220) plane decreased with continuous heating. SAD, selected area diffraction; TEM, transmission electron microscopy; $\mathrm{NiO}$, nickel oxide.

reducing $\mathrm{NiO}$ to nickel by consuming the oxygen of $\mathrm{NiO}$, even in a $\mathrm{N}_{2}$ atmosphere. In air, $\mathrm{NiO}$ maintains its phase because reduction by CNT and reoxidation by $\mathrm{O}_{2}$ molecules occur simultaneously. Moreover, with increasing $\mathrm{NiO}$ content, the oxidation temperature decreased to much lower temperature because of defects in CNT generated by the $\mathrm{NiO}$ loading. The thermal stability of the $\mathrm{NiO} / \mathrm{CNT}$ composite was examined, and it was affected by $\mathrm{NiO}$ and the quantity of defects.

\section{ACKNOWLEDGMENTS}

This work was supported by the National Research Foundation of Korea (NRF) grants funded by the Korea government (MEST; No. 2011-0017257, No. 2011-0019984, and No. 2011-0030803). The authors gratefully appreciate technical support from the Cooperative Center for Research Facilities (CCRF) at Sungkyunkwan University.

\section{RefERENCES}

Ajayan, P.M., Stephan, O., Redlich, P. \& Colliex, C. (1995). Carbon nanotubes as removable templates for metal oxide nanocomposites and nanostructures. Nature 375, 564-567.

Aksel, S. \& Eder, D. (2010). Catalytic effect of metal oxides on the oxidation resistance in carbon nanotube-inorganic hybrids. $J$ Mater Chem 20, 9149-9154.

Avouris, P., Chen, Z. \& Perebeinos, V. (2007). Carbon-based electronics. Nat Nanotechnol 2, 605-615.

Behler, K., Osswald, S., Ye, H., Dimovski, S. \& Gogotsi, Y. (2006). Effect of thermal treatment on the structure of multiwalled carbon nanotubes. J Nanopart Res 8, 615-625. 
Brockner, W., Ehrhardt, C. \& Gjikaj, M. (2007). Thermal decomposition of nickel nitrate hexahydrate, $\mathrm{Ni}\left(\mathrm{NO}_{3}\right)_{2} \cdot 6 \mathrm{H}_{2} \mathrm{O}$, in comparison to $\mathrm{Co}\left(\mathrm{NO}_{3}\right)_{2} \cdot 6 \mathrm{H}_{2} \mathrm{O}$ and $\mathrm{Ca}\left(\mathrm{NO}_{3}\right)_{2} \cdot 6 \mathrm{H}_{2} \mathrm{O}$. Thermochim Acta 456, 64-68.

Brown, S.D.M., Jorio, A., Dresselhaus, M.S. \& Dresselhaus, G. (2001). Observation of the D-band feature in the Raman spectra of carbon nanotubes. Phys Rev B 64, 073403.

Ellingham, H.J.T. (1944). Reducibility of oxides and sulfides in metallurgical processes. J Soc Chem Ind 63, 125-133.

He, K.X., Wu, Q.F., Zhang, X.G. \& WANG, X.L. (2006). Electrodeposition of nickel and cobalt mixed oxide/carbon nanotube thin films and their charge storage properties. J Electrochem Soc 153(8), 1568-1574.

IıjıмA, S. (1991). Helical microtubules of graphitic carbon. Nature 354, 56-58.

Lee, Y.I., Park, M.H., Bae, J.H., Lee, S.E., Song, K.W., Kim, T.H., LEE, Y.H. \& YANG, C.W. (2011). Loading behavior of Pt nanoparticles on the surface of multiwalled carbon nanotubes having defects formed via microwave treatment. J Nanosci Nanotechnol 11, 479-483.

Li, C., Wang, D., Liang, T., Wang, X., Wu, J., Hu, X. \& Liang, J. (2004). Oxidation of multiwalled carbon nanotubes by air: Benefits for electric double layer capacitors. Powder Technol $142,175-179$.

Lota, K., Sierczynska, A. \& Lota, G. (2011). Supercapacitors based on nickel oxide/carbon materials composites. Int J Electrochem 2011, 321473.
Mars, P. \& Krevelen, D.W. (1954). Oxidations carried out by means of vanadium oxide catalysts. Chem Eng Sci 3, 41-59.

Osswald, S., Flahaut, E., Ye, H. \& Gogotsi, Y. (2005). Elimination of D-band in Raman spectra of double-wall carbon nanotubes by oxidation. Chem Phys Lett 402, 422-427.

Osswald, S., Havel, M. \& Gogotsi, Y. (2007). Monitoring oxidation of multiwalled carbon nanotubes by Raman spectroscopy. J Raman Spectrosc 38, 728-736.

Park, Y.S., Choi, Y.C., Kim, K.S., Chung, D.S., Bae, D.J., An, K.H., Lim, S.C., ZHU, X.Y. \& LeE, Y.H. (2001). High yield purification of multiwalled carbon nanotubes by selective oxidation during thermal annealing. Carbon 39, 655-661.

Singleton, M. \& Nash, P. (1989). The C-Ni (carbon-nickel) system. Bulletin of Alloy Phase Diagrams 10(2), 121-126.

WANG, D.W., LI, F. \& Cheng, H.M. (2008). Hierarchical porous nickel oxide and carbon as electrode materials for asymmetric supercapacitor. J Power Sources 185(2), 1563-1568.

XIA, X.H., Tu, J.P., Zhang, J., WANG, X.L., Zhang, W.K. \& HuAng, H. (2008). Electrochromic properties of porous NiO thin films prepared by a chemical bath deposition. Sol Energy Mater Sol Cells 92(6), 628-633.

Zhu, X.Y., Lee, S.M., Lee, Y.H. \& Frauenheim, T. (2000). Adsorption and desorption of an $\mathrm{O}_{2}$ molecule on carbon nanotubes. Phys Rev Lett 85(13), 2757-2760. 